\title{
Hubungan Implementasi IPSG (International Patient Safety Goals) dengan Kepuasan Pasien di Puskesmas Kasihan I Bantul
}

\author{
Anggi Napida Anggraini ${ }^{1}$, Choirul Anwar $^{2}$, Brune Indah Yulitasari ${ }^{3}$ \\ ${ }^{1}$ Administrasi Rumah Sakit, Universitas Alma Ata \\ ${ }^{2}$ Administrasi Rumah Sakit, Universitas Alma Ata \\ ${ }^{3}$ IImu Keperawatan, Universitas Alma Ata \\ Email: angnvd@gmail.com \\ Jalan Brawijaya No.99 Yogyakarta
}

\begin{abstract}
Abstrak
Kepuasan pasien adalah tingkat perasaan pasien yang timbul sebagai akibat dari kinerja pelayanan kesehatan yang diperolehnya setelah pasien membandingkannya dengan apa yang diharapkannya. Sampai saat ini masalah keselamatan pasien Rumah Sakit masih menjadi masalah global, Joint Commission International $(\mathrm{JCl})$ \& World Health Organitation, menurut WHO dalam Ismiyati 2013, menyatakan bahwa kejadian infeksi nosocomial di rumah sakit mencapai $9 \%$ (variasi $3-21 \%$ ) atau lebih dari 1,4 juta pasien rawat inap seluruh rumah sakit di dunia. Angka yang terbilang cukup tinggi untuk kejadian dalam penerapan patient safety. Mengetahui hubungan implementasi IPSG (International Patien Savety Goals) dengan kepuasan Pasien di Puskesmas Kasihan I Bantul. Jenis Penelitian ini adalah kuantitatif dengan rancangan penelitian Cross-sectional. Pengambilan sampel mengunakan accidental sampling untuk kepuasan pasien dan purposive sampling untuk tenaga kesehatan. Instrumen penelitian mengunakan kuesioner dan ceklis observasi. Metode analisis yang digunakan adalah Chi Square. Hasil uji statistik menunjukan ada hubungan antara Implementasi IPSG dengan kepuasan pasien dengan nilai $p$-value $0,004(0,005)$.
\end{abstract}

Kata kunci: IPSG, Patient Safety, kepuasan pasien

\section{Relations the Implementation of IPSG (International Patient Safety Goals) with Satisfaction Patients at Puskesmas Kasihan I Bantul}

\begin{abstract}
Satisfaction patients is feeling of patient arising as a result of the performance of the service health who procures after the patient compare it with what he had hoped. Until now safety problems hospital patients still become a global problem, joint commission international (jci) \& amp; world health organitation, quoting from ismiyati 2013, said that the incidence of infection nosocomial in the hospital at 9\% (variation 3-21\%) or more than 1.4 million inpatients the whole house pain in the world. A figure that is quite high for events in the implementation of the patient safety. To know the relationship IPSG (International Patient Savety Goals) with satisfaction patients at Puskesmas Kasihan I Bantul. This research was quantitative research type with Cross-Sectional research. The samples used accidental sampling to satisfaction patients and purposiv sampling for exertion a health. instrumen research use the questionnaire and ceklis observation. Analysis methods used is Chi Square. there is a relationship between implementation IPSG with the satisfaction of patients with value $p$-value 0,004 $(0,005)$.
\end{abstract}

Keywords: IPSG, Patient Safety, satisfaction patients

Received: 28/12/2017; published: 28/05/2018

Anggraini, AN. Anwar, C. Yulitasari, BI. 2018. Indonesian Journal of Hospital Administration Vol. 1 No.1 | 28 


\section{PENDAHULUAN}

Sampai saat ini masalahkeselamatan pasien Rumah Sakit masih menjadi masalah global, mengutip dari Ismiyati 2015 (1), menyatakan bahwa kejadian infeksi nosocomial di rumah sakit mencapai 9\% (variasi 3-21\%) atau lebih dari 1,4 juta pasien rawat inap seluruh rumah sakit di dunia. Angka yang terbilang cukup tinggi untuk kejadian dalam penerapan patient safety (2). Keselamatan pasien adalah pelayanan yang tidak menciderai atau merugikan pasien, dengan demikian pelayanan yang mengandung unsur kesalahan namun tidak sampai merugikan pasien (menciderai fisik, finansial) atau KNC masih ditolerir (2). Seperti dalam Evaluasi Penerapan Patient Safety dalam Pemberian Obat di Puskesmas Kasihan II Bantul.

Menunjukan bahwa penerapan Patient Safety dalam pemberian obat berdasarkan 6 prinsip benar menunjukan $100 \%$ prinsip benar rute dan kadaluwarsa telah dilaksanakan dan $78,5 \%$ prinsip benar pasien, 63,7\% benar obat, $94,1 \%$ benar dosis dan $25,5 \%$ benar informasi telah dilakukan pada Puskesmas Kasihan II. Sedangkan hasil wawancara dengan 2 responden, responden mengatakan biasanya memberikan dosis obat tidak sesuai dengan yang disarankan Dokter tetapi sesuai dengan stok obat yang ada, halhal seperti ini dapat mengancam keselamatan pasien (3).

Tujuan keselamatan pasien di Rumah Sakit menurut DepKes (4) antara lain sebagai berikut: Terciptanya budaya keselamatan psien di Rumah Sakit; Meningkatnya akuntabilitas Rumah Sakit terhadap pasien dan masyarakat pada umumnya;
Menurunnya angka kejadian tidak diinginkan (KTD) di Rumah Sakit. Terlaksananya program-program pencegahan sehingga harapannya tidak terjadi pengulangan KTD.

Adapun sasaran Patient safety adalah (4): Ketepatan identifikasi pasien. Peningkatan Komunikasi yang efektif. Peningkatan Keamanan Obat yang perlu di waspadai. Kepastian Tepat Lokasi, Tepat Prosedur, Tepat Pasien Operasi. Pengurangan resiko Infeksi dan Pengurangan pasien jatuh.

Kepuasan secara umum adalah persepsi teradap produk atau jasa yang telah memenuhi harapannya. Kepuasan sebagai model kesenjangan antara harapan (standar kinerja yang seharusnya) dengan kinerja aktual yang diterima pelanggan. Comparsion Standard ialah standar yang digunakan untuk menilai ada tidaknya kesenjangan antara apa yang dirasakan pasien dengan standar yang telah di tentukan Standar dapat berasal dari harapan pasien, bagaimana pasien mengharapkan produk atau jasa yang seharusnya diterima, Pesaing. Pasien mengadopsi standar kinerja pesaing rumah sakit untuk kategori produk atau jasa yang sama sebagai standar perbandingan, Kategori produk atau jasa yang lain, produk ini merupakan kepemilikan yang bersifat fisik antara gedung dan dekorasi (5). Adapun Indikator kepuasan pasien dalam akses dan mutu pelayanan kesehatan antara lain (6): Sejauh mana layanan kesehatan itu tersedia pada waktu dan tempat saat dibutuhkan. Kemudahan memperoleh layanan kesehatan, baik dalam keadaan biasa maupun keadaan darurat. Sejauh mana pasien mengerti bagaimana layanan kesehatan itu bekerja, 
keuntungan dan tersedianya layanan kesehatan. Kompetensi

dokter, perawat, dan profesi kesehatan lain yang berhubungan dengan pasien dan Keluaran dari penyakit atau bagaimana perubahan yang dirasakan oleh pasien sebagai hasil dari layanan kesehatan.

\section{BAHAN DAN METODE}

Jenis penelitian ini adalah kuantitatif dengan menggunakan rancangan Cross Sectional (7). Dengan jumlah sampel sebanyak 51 pasien rawat jalan dan 20 tenaga kesehatan yang terdiri dari Dokter, Perawat, Apoteker dan petugas Lab. Penelitian ini dilakukan di Puskesmas Kasihan I Bantul Yogyakarta. Tekhnik pengambilan sampel untuk kepuasan pasien menggunakan accidental sampling, sedangkan untuk Patient Safety adalah purposive sampling.

\section{HASIL DAN PEMBAHASAN}

Tabel 1 Hasil Analisis Distribusi Frekuensi Karakteristrik Responden Berdasarkan Jenis Kelamin dan Usia

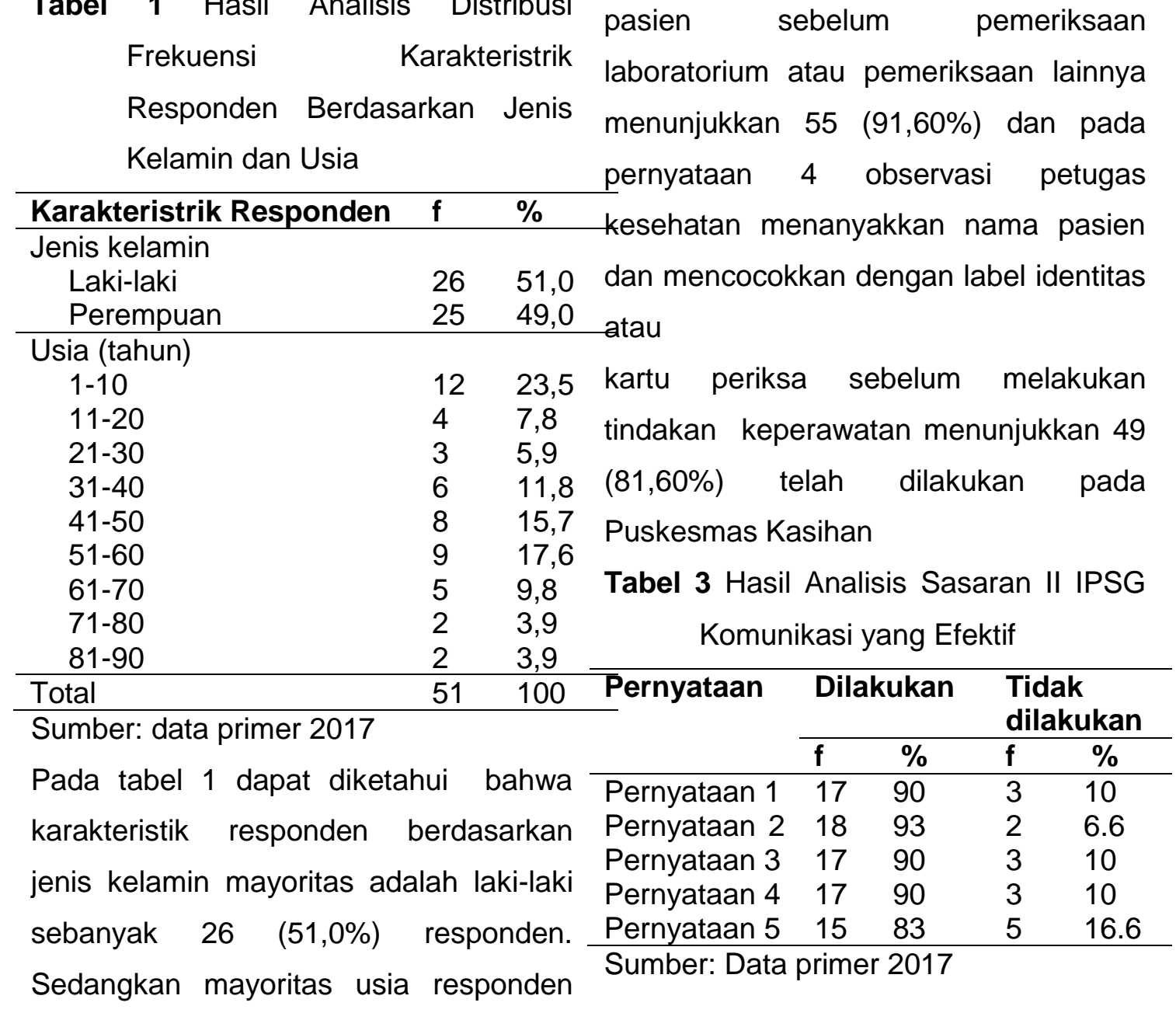

adalah 1-10 tahun sebanyak 12 (23,5\%) responden.

Tabel 2 Hasil Analisis Sasaran I IPSG. Observasi Identifikasi Pasien dengan Benar

\begin{tabular}{lllll}
\hline Pernyataan & \multicolumn{2}{l}{ Dilakukan } & \multicolumn{2}{l}{$\begin{array}{l}\text { Tidak } \\
\text { dilakukan }\end{array}$} \\
\cline { 2 - 6 } & f & $\%$ & f & $\%$ \\
\hline Pernyataan 1 & 59 & 98,30 & 1 & 1,6 \\
Pernyataan2 & 60 & 100 & 05 & 0 \\
Pernyataan 3 & 55 & 91,60 & 11 & 8,3 \\
Pernyataan 4 & 49 & 81,60 & & 18,3 \\
\hline
\end{tabular}

Sumber: Data primer 2017

Tabel 2 Menunjukkan setelah dilakukan 60 kali observasi bahwa penerapan patient safety dalam pernyataan 1 Identifikasi Pasien dengan benarberdasarka observasi petugas kesehatan mengidentifikasi minimal 2 identitas pasien menunjukkan 59 (98,30\%), untuk pernyataan 2 observasi petugas kesehatan menyakan nama pasien dan mencocokkan dengan label identitas atau kartu periksa sebelum pemberian obat menunjukkan 60 (100\%), pernyataan 3 observasi pada petugas kesehatan menanyakan nama pasien sebelum pemeriksaan laboratorium atau pemeriksaan lainnya menunjukkan 55 (91,60\%) dan pada pernyataan 4 observasi petugas 
Tabel 3 Menunjukkan setelah dilakukan 20 kali observasi bahwa penerapan patient safety dalam komunikasi yang efektif, pernyataan 1 komunikasi petugas kesehatan memberikan perintah dengan lengkap secara lisan kepada rekan kerja menunjukkan 27 (90\%), pernyataan 2 petugas kesehatan memberikan perintahdengan lengkap via telpon kepada rekankerja menunjukkan 28 (93\%), pernyataan 3 petugas kesehatan menginformasikanulang perintah yang diterimamenunjukkan 27 (90\%), untuk pernyataan 4 prosedur verifikasi padakomunikasi lisan dijalankan secara konsisten oleh petugas kesehatan menunjukkan 27 (90\%), dan sedangkan untuk pernyataan 5 prosedur verifikasi pada komunikasi via telpon yang dijalankan secara konsisten oleh petugas kesehatan menunjukkan 25 (83\%) telahterlaksana pada Puskesmas Kasihan I. Penelitian ini di dukung penelitian sebelumnya yang menyatakan komunikasi efektif bisa melalui komunikasi S-BAR dan akan meningkatkan keamaan pemberian obat oleh petugas kesehatan (8).

Tabel 4 Hasil Analisis Sasaran III IPSG Observasi Pemberian Obat

\begin{tabular}{llcll} 
Prinsip & \multicolumn{2}{c}{ Dilakukan } & \multicolumn{2}{l}{$\begin{array}{l}\text { Tidak } \\
\text { dilakukan }\end{array}$} \\
\cline { 2 - 5 } & f & $\%$ & f & $\%$ \\
\hline Pasien & 10 & 100 & 0 & 0 \\
Rute & 10 & 100 & 0 & 0 \\
Obat & 10 & 100 & 0 & 0 \\
Dosis & 10 & 100 & 0 & 0 \\
Informasi & 7 & 70 & 3 & 30 \\
Kadaluwarsa & 10 & 100 & 0 & 0 \\
Observasi & 10 & 100 & 0 & 0 \\
\hline
\end{tabular}

Sumber: Data primer 2017

Tabel 4 Menunjukkan setelah dilakukan 10 kali observasi bahwa penerapan patient safety dalam pemberian obat berdasarkan 6 prinsip benar menunjukkan prinsip benar pasien, prinsip benar rute, benar obat dan prinsip benar dosis prinsip kadaluwarsa menunjukkan $100 \%$ telah dilakukan pada Puskesmas Kasihan I.

Tabel 5 Hasil Analisis Sasaran IV Risiko Infeksi

\begin{tabular}{lllll}
\hline Pernyataan & \multicolumn{2}{c}{ Dilakukan } & \multicolumn{2}{c}{$\begin{array}{l}\text { Tidak } \\
\text { dilakukan }\end{array}$} \\
\cline { 2 - 5 } & f & $\%$ & f & $\%$ \\
\hline Pernyataan 1 & 1 & 10 & 9 & 90 \\
Pernyataan 2 & 10 & 100 & 0 & 0 \\
Pernyataan 3 & 10 & 100 & 0 & 0 \\
Pernyataan 4 & 10 & 100 & 0 & 0 \\
Pernyataan 5 & 8 & 80 & 2 & 20 \\
\hline Observasi & & & & \\
\hline Pernyataan 1 & 1 & 100 & 0 & 0 \\
Pernyataan 2 & 1 & 100 & 0 & 0 \\
Pernyataan 3 & 1 & 100 & 0 & 0 \\
\hline Sumber: Data & & & &
\end{tabular}

Sumber: Data primer 2017

Tabel 5 Menunjukkan setelah dilakukan 10 kali observasi bahwa penerapan patient safety dalam risiko infeksi pernyataan 1 dengan observasi petugas kesehatan mencuci tangan dengan 6 langkah menunjukkan 1 (10\%), pernyataan 2 observasi petugas kesehatan mencuci tangan setiap mau melakukan tindakan perawatan menunjukkan 10 (100\%), pernyataan 3 observasi petugas kesehatan mencuci tangan setiap setelah tindakan perawatan menujukkan 10 (100\%).

Tabel 6 Sasaran V IPSG Risiko Jatuh

\begin{tabular}{llcll}
\hline Pernyataan & \multicolumn{2}{l}{ Dilakukan } & \multicolumn{2}{c}{$\begin{array}{l}\text { Tidak } \\
\text { dilakukan }\end{array}$} \\
\cline { 2 - 5 } & $\mathbf{f}$ & $\%$ & $\mathbf{f}$ & $\%$ \\
\hline Pernyataan 1 & 5 & 100 & 0 & 0 \\
Pernyataan 2 & 5 & 100 & 0 & 0 \\
Pernyataan 3 & 5 & 100 & 0 & 0 \\
Pernyataan 4 & 5 & 100 & 0 & 0 \\
Observasi & & & & \\
Pernyataan 1 & 1 & 100 & 0 & 0 \\
Pernyataan 2 & 1 & 100 & 0 & 0 \\
Pernyataan 3 & 1 & 100 & 0 & 0 \\
Pernyataan 4 & 1 & 100 & 0 & 0 \\
Pernyataan 5 & 1 & 100 & 0 & 0 \\
Pernyataan 6 & 1 & 100 & 0 & 0 \\
Pernyataan 7 & 0 & 0 & 1 & 100 \\
& & & &
\end{tabular}

Sumber: Data primer 2017

Tabel 6 menunjukkan setelah dilakukan 5 kali observasi bahwa penerapan patient safety dalam Risiko Cedera/Risiko Jatuh dengan observasi pernyataan 1 petugas melakukan skreening risiko pasien jatuh 5 atau $100 \%$ telah dilakukan pada Puskesmas 
Kasihan I, sedangkan yang tidak melakukan penerapan pada observasi pernyataan 7 lantai pintu masuk pelayanan kesehatan tidak bertangga menunjukkan $0 \%$ telah dilakukan pada Puskesmas Kasihan I.

Tabel 7 Hasil Analisis Distribusi Frekuensi Tingkat Kepuasan pada Pasien Di Puskesmas Kasihan 1 Bantul Yogyakarta

\begin{tabular}{lll}
\hline $\begin{array}{l}\text { Tingkat } \\
\text { Kepuasan }\end{array}$ & $\mathbf{f}$ & $\%$ \\
\hline Tidak Puas & 0 & 0 \\
Cukup Puas & 8 & 15,7 \\
Puas & 29 & 56,9 \\
Sangat Puas & 14 & 27,5 \\
\hline Total & 51 & 100 \\
\hline
\end{tabular}

Sumber: Data primer 2017

Pada Tabel 7 menunjukan kategori terbanyak pasien menyatakan puas sebanyak 29 (56,9\%) dan kategori terendah pasien menyatakan cukup puas sebanyak 8 (15,7\%).

Tabel 8 Hasil Analisis Tabulasi Silang

\begin{tabular}{|c|c|c|c|c|c|c|c|}
\hline \multirow[t]{2}{*}{$\begin{array}{l}\text { Kepuasan } \\
\text { Pasien }\end{array}$} & \multicolumn{2}{|c|}{$\begin{array}{l}\text { Dilakuka } \\
\text { n }\end{array}$} & \multicolumn{2}{|c|}{$\begin{array}{l}\text { Tidak } \\
\text { Dilakukan }\end{array}$} & \multicolumn{2}{|c|}{ Total } & \multirow[t]{2}{*}{$\begin{array}{l}\mathbf{P} \\
\text { Value }\end{array}$} \\
\hline & $f$ & $\%$ & f & $\%$ & $f$ & & \\
\hline $\begin{array}{l}\text { Cukup } \\
\text { Puas }\end{array}$ & 2 & 3,9 & 6 & 11,8 & 8 & 15,7 & 0,004 \\
\hline Puas & 0 & 0 & 29 & 56,9 & 29 & 56,9 & \\
\hline $\begin{array}{l}\text { Sangat } \\
\text { Puas }\end{array}$ & 0 & 0 & 14 & 27,5 & 14 & 27,5 & \\
\hline
\end{tabular}

Sumber: Data primer 2017

Berdasarkan hasil uji statistik menggunakan uji chi-square di dapatkan hasil nilai $p$-value sebesar 0,004 $(<0,005)$, Ho ditolak dan $\mathrm{Ha}$ di terima yang berarti terdapat hubungan antara Implementasi IPSG (International Patient Safety Goals) dengan Kepuasan Pasien di Puskesmas Kasihan I Bantul.

Implementasi

IPSG (International

Patient Safety Goals)

Sasaran I Observasi Identifikasi Pasien dengan Benar

Hasil penelitian ini menunjukkan bahwa dari 60 kali observasi tenaga kesehatan mayoritas telah melakukan sasaran I patient safety dengan persentase $92,8 \%$ hal ini menunjukkan Implementasi IPSG (International Patient
Safety Goals) sasaran I di Puskesmas Kasihan I bantul sudah terlaksana. Berdasarkan hasil yang didapatkan dengan presentase menunjukkan bahwa, penerapan patient safety dalam Identifikasi Pasien sudah terlaksana dengan benar. Berdasarkan observasi petugas kesehatan mengidentifikasi minimal 2 identitas pasien menunjukkan 98,30\%. hal ini menunjukkan bahwa mayoritas tenaga kesehatan sudah mengidentifikasi minimal 2 identitas pasien, untuk observasi petugas kesehatan menanyakan nama pasien dan mencocokkan dengan label identitas atau kartu periksa sebelum pemberian obat menunjukkan 100\%, observasi pada petugas kesehatan menanyakan nama pasien sebelum pemeriksaan laboratorium atau pemeriksaan lainnya menunjukkan $91,60 \%$ dan pada observasi petugas kesehatan menanyakan nama pasien dan mencocokkan dengan label identitas atau kartu periksa sebelum melakukan tindakan/prosedur keperawatan menunjukkan $81,60 \%$ telah dilakukan pada Puskesmas Kasihan I. Hal ini juga di dukung oleh fatimah (9) untuk mengurangi kesalahan pengobatan petugas kesehatan termasuk perawat diupayakan menerapkan prinsip benar pemberian obat. Selanjutnya penelitian Angelita Lombogia. 2016, dengan hasil penelitian menunjukkan bahwa kemampuan patient safety dalam mengidenifikasi pasien besar baik dengan jumlah 23 responden $(74,2 \%)$ (10). Hal ini mempengaruhi Tingkat kepuasan pasien, kepuasan pasien merupakan model dari kesenjangan antara harapan dengan kinerja aktual yang diterima oleh pasien, 
pada kategori sasaran ketepatan identifikasi pasien pada Puskesmas Kasihan 1 Bantul mayoritas tahapan identifikasi pasien telah dilakukan dengan prosedur yang telah ditetapkan dan melakukan pengecekkan kembali setelah melakukan tindakan. Hal ini juga didukung dengan penelitian yang dilakukan oleh Thisna dengan judul Hubungan Pelaksanaan Identifikasi Pasien Secara Benar dengan Kepuasan Pasien di Instalasi Gawat Darurat hasil penelitian menunjukkan bahwa dari 93 responden didapatkan jumlah identifikasi pasien secara benar sebanyak 60 responden $(64,5 \%)$ (11).

\section{Sasaran II Komunikasi yang Efektif}

Hasil penelitian ini menunjukkan bahwa dari 20 kali observasi tenaga kesehatan mayoritas telah melaksanakan penerapan patient safety sasaran II dengan persentase 89,2\%. Hal ini menunjukkan penerapan Implementasi IPSG (International Patient Safety Goals) sasaran II di Puskesmas Kasihan I Bantul telah terlaksana dengan presentasi petugas kesehatan memberikan perintah dengan lengkap secara lisan kepada rekan kerja menunjukkan 90\%, sasaran petugas kesehatan memberikan perintah dengan lengkap via telpon kepada rekan kerja menunjukkan

93\%, sasaran petugas kesehatan menginformasikan ulang perintah yang diterima menunjukkan 90\%, untuk prosedur verifikasi pada komunikasi lisan dijalankan secara konsisten oleh petugas kesehatan menunjukkan 90\%, dan sedangkan untuk sasaran prosedur verifikasi pada komunikasi via telpon yang dijalankan secara konsisten oleh petugas kesehatan menunjukkan
83\% telah terlaksana pada Puskesmas Kasihan I. Puskesmas Kasihan I Bantul pada penerapan komunikasi yang efektif telah dilakukan oleh semua petugas guna meningkatkan kepuasan pasien, komunikasi yang efektif digunakan oleh petugas kesehatan dengan memastikan petugas tepat waktu, akurat memberikan informasi mudah dipahami oleh pasien guna mengurangi kesalahan dan meningkatkan keselamatan pasien. Hal ini juga di dukung oleh penelitian yang dilakukan oleh Dian Lestarina dengan judul Hubungan Komunikasi Terapiutik dengan Kepuasan Pasien Paska Oprasi di Rawat Inap dengan hasil nilai ratarata komunikasi terpitik sebesar 56,06\% (12).

\section{Sasaran Observasi Pemberian Obat} di Puskesmas Kasihan I

Hasil

observasi

menunjukkan bahwa mayoritas tenaga kesehatan sudah melakukan prinsip 6 benar dalam pemberian obat dengan presentasi, benar pasien menunjukan $100 \%$, benar rute menunjukan $100 \%$, benar obat menunjukan $100 \%$, benar dosis menunjukan 100\%, benar kadaluwarsa menunjukan 100\%, observasi terdapat SOP prinsip pemberian obat menunjukan 100\%, observasi terdapat tempat khusus penyimpanan obat-obatan yang telah kadaluwarsa menunjukan $100 \%$, observasi adanya system return obat yang mendekati expired date menunjukan $100 \%$, observasi adanya nama obat pada loker penyimpanan menunjukan 100\%, observasi etiket pada obat dalam menunjukan 100\%, dan observasi etiket pada obat luar menunjukan 100\%. sedangkan untuk benar informasi minoritas belum 
dilaksanakan tenaga kesehatan dengan persentase $70 \%$.

hal ini menunjukan penerapan Implementasi IPSG (International Patient Safety Goals) sasaran III belum terlaksana dengan persentase 95,7\%. Hal ini juga di dukung oleh penelitian yang dilakukan Napida dan fatimah dengan hasil penelitian penerapan patient safety dalam pemberian obat berdasarkan prinsip 6 benar menunjukan $100 \%$ prinsip benar rute dan kadaluwarsa telah dilaksanakan dan $75,5 \%$ prinsip benar pasien, 63,7\% benar obat,94,1\% benar dosis, dan 25,5\% benar informasi (3).

\section{Sasaran IV IPSG Risiko Infeksi}

Berdasarkan hasil observasi yang dilakukan di Puskesmas 1 Kasihan Bantul, menunjukkan bahwa penerapan patient safety dalam sasaran IV implementasi IPSG (International Patient Safety Goals) risiko infeksi telah terlaksana dengan presentase $86,25 \%$. Selama observasi petugas kesehatan mencuci tangan dengan 6 langkah menunjukkan 10\%. Hal ini juga di dukung oleh penelitian yang di lakukan Nur Mahya dengan hasil didapatkan dua pertisipan menyatakan bahwa salah satu hambatan dalam melakukan cuci tangan adalah hambatan individu atau personal seperti perilaku atau kebiasaan, termasuk lupa (13).

Observasi petugas kesehatan mencuci tangan setiap sebelum melakukan tindakan perawatan menunjukkan $100 \%$, observasi yang ketiga yaitu petugas kesehatan mencuci tangan setiap setelah tindakan perawatan menujukkan $100 \%$, observasi petugas kesehatan menggunakan hand scrub setiap sebelum keruangan perawatan pasien menunjukkan 100\%, menunjukkan 100\%, observasi pagar untuk observasi petugas kesehatan menggunakan hand scrub setiap setelah dari ruangan perawatan pasien menunjukkan $80 \%$, pada observasi poster yang ditempel ditempatkan yang terbuka berisi tentang cara mencuci tanagn 6 langkah menunjukkan 100\%, observasi mengenai wastafel untuk mencuci tangan menunjukkan $100 \%$, dan untuk observasi Hand srub atau alcohol hand untuk mencuci tangan disetiap ruangan menunjukkan 100\% telah dilakukan pada Puskesmas Kasihan I Bantul.

Hal ini juga di dukung oleh penelitian yang di lakukan Nur Mahya dengan judul Pengalaman Perawat Pelaksana Dalam Menerapkan Keselamatan Pasien dengan hasil Lima partisipan menyatakan bahwa cara untuk mengurangi risiko infeksi adalah melalui cuci tangan. Lima partisipan juga menyebutkan lima waktu cuci tangan atau disebut dengan five moment, yaitu sebelum ke pasien, setelah dari pasien, setelah melakukan tindakan aseptic, setelah terkena cairan pasien, dan setelah dari lingkungan pasien (13).

\section{Sasaran Risiko Jatuh}

Hasil observasil menunjukkan bahwa penerapan patient safety dalam sasaran V Implementasi IPSG (International Patient Safety Goals) Risiko Cedera/Risiko Jatuh sudah terlaksana dengan persentase 90,9\%. Observasi keseluruhan petugas melakukan skreening risiko pasien jatuh, petugas memberikan alat bantu jalan pada pasien yang beresiko jatuh, observasi petugas kesehatan mengajari pasien tentang cara penggunaan bel menunjukkan $100 \%$, observasi tempat tidur dalam keadaan terkunci 
pengaman tempat tidur dinaikkan menunjukkan $100 \%$, terdapat pengaman (handrails) dikamar mandi menunjukkan $100 \%$, observasi lantai kamar mandi pelayanan kesehatan tidak licin menunjukkan 100\%, observasi lantai tangga pelayanan kesehatan tidak licin menunjukkan $100 \%$, observasi lantai tangga pelayananan kesehatan ada tanda khusus yang dicapai yaitu 100\% telah dilakukan pada Puskesmas Kasihan I, sedangkan yang tidak melakukan penerapan patient safety pada sasaran $\mathrm{V}$ adalah pada ceklis lantai pintu masuk pelayanan kesehatan tidak bertangga menunjukkan $0 \%$ telah dilakukan pada Puskesmas Kasihan I.

Hal ini juga di dukung oleh penelitian yang di lakukan isnaini dengan judul Pengalaman Perawat Pelaksana Dalam Menerapkan Keselamatan Pasien dengan hasil Lima partisipan menyatakan setelah pasien diketahui berisiko jatuh, partisipan akan melakukan intervensi terkait risiko jatuh seperti memasang pengaman samping bed dan memperhatikan lingkungan sekitar yang menyebabkan pasien jatuh, mendampingi pasien saat mobilisasi, serta mengedukasi keluarga tentang risiko jatuh yang dialami pasien (13).

\section{Kepuasan Pasien}

Hasil penelitan ini menunjukkan bahwa tingkat kepuasan pasien di Puskesmas Kasihan I Bantul menunjukan bahwa kategori terbanyak pasien menyatakan puas sebanyak 29 (56,9\%) dan katagori terendah pasien menyatakan cukup puas sebanyak 8 $(15,7 \%)$. Hal ini dapat terlihat pada jawaban pasien yang menyatakan mayoritas menjawab sangat puas terhadap perawat yang selalu tersenyum saat bertemu pasien, pasien menyatakan perawat mendengarkan keluhan atau pernyataan pasien dengan penuh perhatian.

Menurut Anwar Hafidz (6) salah satu indikator kepuasan pasien adalah Kepuasan terhadap proses layanan kesehatan, dimana Persepsi tentang perhatian dan kepedulian dokter dan atau layanan kesehatan lain. Sedangkan menurut Nursalam (5)Kepuasan merupakan sebagai model kesenjangan antara harapan (standar kinerja yang seharusnya) dengan inerja aktual yang diterima pelanggan.

Hasil penelitian ini didukung oleh penelitian yang dilakukan oleh Priciliya Hubungan Komunikasi Trapeotik dengan kepuasan pasien di ruang rawat inap dengan hasil dari 67 responden mengenai kepuasan pasien berdasarkan keterampilan komunikasi trapiutik merasa puas 47 responden $(70,1 \%)$ dan yang merasa kurang puas dengan komunikasi terapiutik sebanyak 20 responden (29,9\%) (14).

\section{Hubungan Implementasi IPSG (International Patient Safety Goals) dengan Kepuasan Pasien di Puskesmas Kasihan I Bantul.}

Berdasarkan data yang didapatkan dalam penelitian ini didapatkan hasil mayoritas responden menyatakan puas dengan pelaksanaan patien safety sebanyak 41 responden $(96,1 \%)$. Penelitian ini terdapat hubungan antara Implementasi IPSG dengan kepuasan pasien di Puskesmas Kasihan I Bantul. Hasil penelitian ini juga didukung oleh penelitian yang dilakukan oleh Thisna dengan judul hubungan pelaksanaan identifikasi pasien secara 
benar dengan kepuasan pasien di instalasi gawat darurat. Bahwa pasien yang diidentifikasi secara benar dan yang merasa puas ada 54 responden $(90,0 \%)$ sedangkan yang diidentifikasi pasien secara tidak benar dan yang merasa tidak puas ada 6 responden (10\%) sedangkan pasien yang diidentifikasi secara tidak benar dan yang merasa puas ada 2 responden $(6,1 \%)$.

Menurut WHO dalam (4) Keselamatan pasien adalah tidak adanya bahaya yang ditimbulkan yang dapat dicegah kepada pasien selama proses perawatan kesehatan. Disiplin keselamatan pasien merupakan upaya terkoordinasi untuk mencegah kerusakan yang disebabkan oleh proses perawatan kesehatan yang dapat terjadi pada pasien. Sedangkan menurut DepKes (4) salah satu tujuan keselamatan pasien adalah terciptanya budaya keselamatan pasien.

Terciptannya kepuasaan pasien tentunya tidak terlepas dari kinerja dan mutu pelayanan petugas yang ada dipuskesmas. Menurut Satrianegara (15) salah satu faktor yang mempengaruhi tingkat kepuasan pasien adalah Wujud dari kinerja misalnya kecepatan, kemudahan, dan kenyamana bagaimana perawat dalam memberikan jasa pengobatan terutama keperawatan pada waktu penyembuhan yang relatif cepat, kemudahan dalam memenuhi kebutuhan pasien dan kenyamanan dengan memperhatikan kebersihan.

Menurut WHO dalam DepKes (2) Patient safety merupakan Keselamatan pasien tidak adanya bahaya yang ditimbulkan yang dapat dicegah kepada pasien selama proses perawatan kesehatan. Disiplin keselamatan pasien merupakan upaya terkoordinasi untuk mencegah kerusakan yang disebabkan oleh proses perawatan kesehatan yang dapat terjadi pada pasien.

Implementasi patient safety akan meningkatkan mutu serta kualitas rumah sakit dalam melaksanakan pelayanan kesehatan untuk pasien (16).

\section{SIMPULAN DAN SARAN}

Terdapat hubungan antara Implementasi IPSG dengan kepuasan pasien di puskesmas Kasihan I Bantul dengan nilai $p$-value 0,004 .

\section{DAFTAR PUSTAKA}

1. Ismiyati R. Hubungan pengetahuan perawat tentang patient safety dengan perilaku perawat dalam pencegahan kejadian Plebitis di Ruang rawat inap Rumah Sakit Panti Waluyo Surakarta. 2015;

2. DepKes RI. Panduan nasional keselamatan pasien rumah sakit (patient safety). Depkes RI Jakarta. 2008;

3. Anggraini AN, Fatimah FS. Evaluasi Penerapan Patient Safety dalam Pemberian Obat di Wilayah Kerja Puskesmas Kasihan II Kabupaten Bantul Yogyakarta. J Ners dan Kebidanan Indones. 2015;3(3):1628.

4. Departemen Kesehatan RI. Panduan nasional keselamatan pasien rumah sakit (Patient Safety). Jakarta Depkes RI. 2008;

5. Nursalam. Manajemen Keperawatan Aplikasi dalam Praktek Keperawatan Profesional. 3rd ed. Jakarta: Salemba Medika; 2011.

6. Hafid MA. Hubungan Kinerja Perawat Terhadap Tingkat Kepuasan Pasien Pengguna 
Yankestis Dalam Pelayanan Keperawatan Di RSUD Syech Yusuf Kab. Gowa. J Kesehat. 2014;7(2).

7. Hidayat AAA. Metode penelitian keperawatan dan teknik analisis data. 1st ed. Jakarta: Medika Salemba; 2007.

8. Fatimah FS, Rosa EM. Efektivitas Pelatihan Patient Safety; Komunikasi S-BAR pada Perawat dalam Menurunkan Kesalahan Pemberian Obat Injeksi di Rumah Sakit PKU Muhammadiyah Yogyakarta Unit II Effectiveness Patient Safety Training; SBAR Communication in Nursing to Reduce of Er. Ef Pelatih Patient Saf; Komun S-BAR pada Perawat dalam Menurunkan Kesalahan Pemberian Obat Injeksi di Rumah Sakit PKU Muhammadiyah Yogyakarta Unit II Eff Patient Saf Train; SBAR Commun Nurs to Reduce Er. 2014;2(1):32-41.

9. Fatimah FS. Gambaran Penerapan Prinsip Benar Pemberian Obat di Rumah Sakit PKU Muhammadiyah Yogyakarta Unit II. J Ners dan Kebidanan Indones. 2016;4(2):79.

10. Lombogia A, Julia R, Karundeng M. Hubungan Perilaku Dengan Kemampuan Perawat Dalam Melaksanakan Keselamatan Pasien (Patient Safety) Di Ruang Akut Instalasi Gawat Darurat Rsup Prof. Dr. RD Kandou Manado. J KEPERAWATAN. 2016;4(2).
11. Umaternate $T$, Kumaat L, Mulyadi N. Hubungan Pelaksanaan Identifikasi Pasien Secara Benar Dengan Kepuasan Pasien Di Instalasi Gawat Dadurat (lgd) Rsup Prof. Dr. RD Kandou Manado. J KEPERAWATAN. 2015;3(2).

12. Liestriana D, Rejeki S, Wuryanto $E$. Hubungan Komunikasi Terapeutik Dengan Kepuasan Pasien Pasca Operasi Rawat Inap Di Rsud Kajen Kabupaten Pekalongan. FIKkeS. 2012;5(1).

13. Isnaini NM. Pengalaman Perawat pelaksana dalam Menerapkan Keselamatan Pasien. J Manag Keperawatan. 2014;2(1).

14. Lombogia A, Rottie J, Karundeng M. Hubungan Perilaku dengan Kemampuan Perawatn dalam Melaksanakan Keselamatan Pasien (Patient safety) di Ruang Akut Instalasi Gawat Darurat RSUP PROF. DR. R. D. Kandou Manado. 2016;4(2). Available from: http://ejournal.unsrat.ac.id/index.php /jkp/article/viewFile/12916/12503

15. Satrianegara F, Saleha S. Organization dan Manajemen Pelayanan Kesehatan serta Kebidanan. Jakarta: Salemba Medika; 2009.

16. Sumarni. Analisis Implementasi Patient Safety Terkait Peningkatan Mutu Pelayanan Kesehatan di Rumah Sakit. J Ners dan Kebidanan Indones. 2017;5(2):91-9. 